\title{
Estimation of Global Solar Radiation using Modified Angstrom Empirical formula on the basis of Meterological parameters in Himalaya Region Pokhara, Nepal
}

\author{
Khem N. Poudyal \\ Department of Engineering Science and Humanities, Pulchowk Campus, Institute of Engineering \\ Tribhuvan University, Kathmandu, Nepal \\ corresponding author:khem@ioe.edu.np
}

\begin{abstract}
This research work proposes the coefficient equation of modified Angstrom model using sunshine hour and meteorological parameters for the estimation of global solar radiation in Himalaya Region Pokhara $\left(28.22^{\circ} \mathrm{N}, 83.32^{\circ} \mathrm{E}\right)$, Nepal . This site is about $800.0 \mathrm{~m}$ above from the sea level lying just $20.0 \mathrm{~km}$ south of the Machhaputre Himalayas. The model coefficients $\mathrm{a}$ and $\mathrm{b}$ obtained in this research are 0.43 and 0.23 respectively. The performance parameters of the model are: Root Mean Square Error RMSE $=0.13 \mathrm{MJ} / \mathrm{m}^{2} /$ day, Mean Bias Error MBE $=0.02 \mathrm{MJ} / \mathrm{m}^{2} /$ day Mean Percentage $\mathrm{MPE}=5$ percent and coefficient of determination $\mathrm{R}^{2}=0.70$.
\end{abstract}

Keywords: global solar radiation, sunshine hour, empirical formula, clearness index, regression analysis

\section{Introduction}

The global or total solar radiation is the fundamental input for design, optimization and performance evaluation of solar technologies and applications such as photovoltaic and solar thermal systems for any specific location. However, for many developing countries including Nepal, solar radiation measurements are not readily available lack of financial constraint associated with acquiring the solar radiation data. The national average sunshine duration and solar insolation are 6.8/day and $4.7 \mathrm{kWh} / \mathrm{sq} . \mathrm{m} /$ day respectively. However the energy scenario of Nepal is alarming situation because of 6 to 16 hours loads shedding per day at rainy season and dry season respectively [1].

In this situation, it is only option to develop the best possible methods or select the appropriate models to find out the authentic data of global solar radiation [2]. There are several types of empirical formulae for estimating the monthly mean daily global solar radiation as a function of readily measured climatic data $[3,4,5]$. It is known that the simplest regression relation is Angstrom-Prescott, which relates the monthly mean daily global solar radiation to the number of hours of bright sunshine. This paper explains on modified Angstrom formula and linear regression techniques used to estimate the regression coefficients for the estimation of global solar radiation using sunshine duration.

\section{Methods and Instrumentation}

The global solar radiation on a horizontal surface was measured using Kipp and Zonen CMP6 Pyranometer at Pokhara. This instrument is installed near Pokhara Airport. The CMP6 
Pyranometer is shown in figure 1.

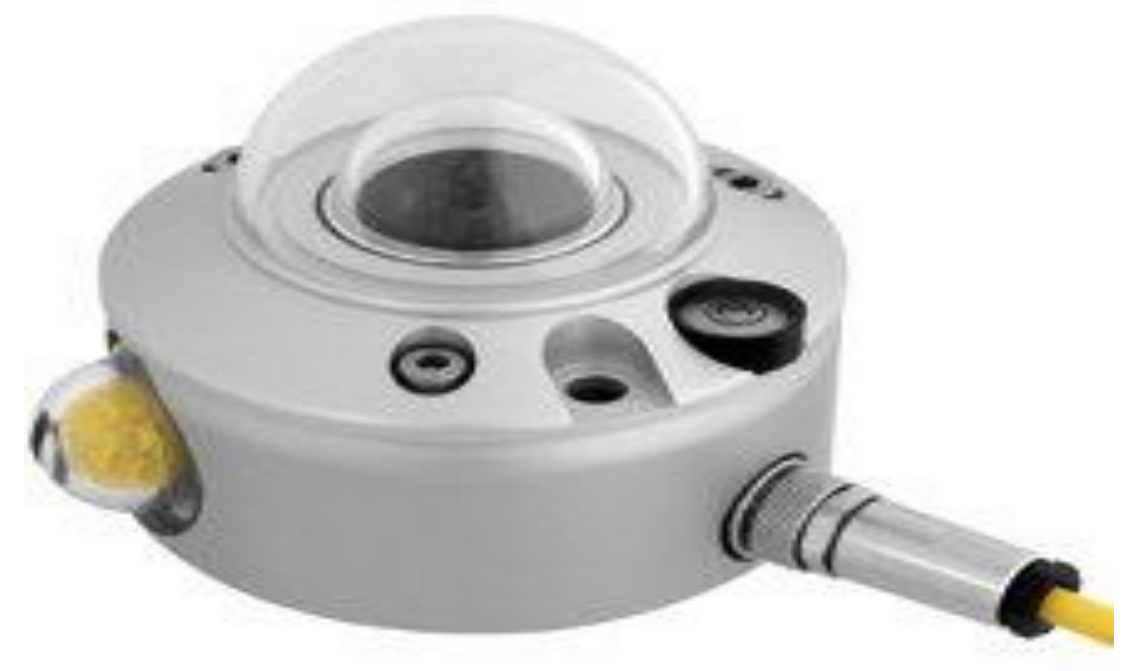

Figure 1. CMP6 Pyranometer

This CMP6 Pyranometer is first class among the different Pyranometers. Its operating temperature ranges from $-40^{\circ} \mathrm{C}$ to $80^{\circ} \mathrm{C}$. It has wide spectral range of instrument from $310 \mathrm{~nm}$ to $2800 \mathrm{~nm}$. The sensitivity of instrument and field of view are 5 to $15 \mu \mathrm{V} / \mathrm{W} / \mathrm{m}^{2}$ and $180^{\circ}$ respectively. In this instrument, the measuring data is recorded by LOGBOX SD data logger within a minute resolution for 24 hours. Its special features are low noise, high resolution and low power consumption. It works in all weather conditions. It collects the data at real time for the needs of meteorology and slow signal analysis. We can insert the SD memory card for long term data storage. For the communication LOGBOX uses either RS232 or RS485 communication port [6].

The global solar radiation $\left(\mathrm{H}_{\mathrm{g}}\right)$ is measured using CMP6 Pyranometer on the horizontal surface at Pokhara. The relation of extraterrestrial global solar radiation $\mathrm{H}_{0}$ is calculated using equation (1.10.3) [7].

$$
H_{0}=\frac{24}{\pi} I_{s c}\left(1+0.033 \operatorname{Cos} \frac{360}{365} n\right)\left(\omega \frac{\pi}{180} \operatorname{Sin} \phi \operatorname{Sin} \delta+\operatorname{Cos} \phi \operatorname{Cos} \delta \operatorname{Sin} \omega\right)
$$

where $\mathrm{H}_{0}$ is monthly mean of daily global extraterrestrial solar radiation $\left(\mathrm{MJ} / \mathrm{m}^{2} /\right.$ day $), \mathrm{H}_{\mathrm{g}}$ is monthly mean of daily global solar radiation $\left(\mathrm{MJ} / \mathrm{m}^{2} /\right.$ day),$\varphi$ is the $\emptyset$ is latitude ( $\left.\mathrm{rad}\right)$ and $\delta$ is the solar declination angle (rad). $\omega$ is sunset hour angle for typical day and $\mathrm{n}$ is mean day of each months

where, $\mathrm{n}$ is the day of the year. January first $\mathrm{n}=1$ to 365 days.

$$
\delta=23.45 \operatorname{Sin}\left(\frac{360}{365}(284+n)\right)
$$

The relation of day length is, $\quad N=\frac{2}{15} \operatorname{Cos}^{-1}(-\operatorname{Tan} \phi \operatorname{Tan} \delta)$

$$
\omega=\operatorname{Cos}^{-1}(-\operatorname{Tan} \phi \operatorname{Tan} \delta)
$$

where $\omega$ is the sunset hour angle 
160 Estimation of Global Solar Radiation using Modified Angstrom Empirical formula on the basis.......

On the basis of $\mathrm{R}^{2}$, the $\mathrm{H}_{\mathrm{o}} / \mathrm{H}_{0}$ can be found using the linear equation and after applying the equation (1) for the extraterrestrial global solar radiation is found. At the end $\mathrm{H}_{\mathrm{g}}$ can be calculated which will be novel work where all types of measuring instruments could not be installed.

\section{Results and Discussion}

\subsection{Daily Variation of Global Solar Radiation in Pokhara}

The diurnal variation of global solar radiation varies due to inclination, solar zenith angle, altitude, change in season and local weather condition. Figure 3.2 shows the daily variation of global solar radiation at the measurement site Pokhara. The maximum solar radiation is found to be $28.86 \mathrm{MJ} /$ $\mathrm{m}^{2} /$ day on $4^{\text {th }}$ of June. The given figure shows that there is comparatively less amount of global solar radiation is found at the summer season due the excess clouds and rain at that time.

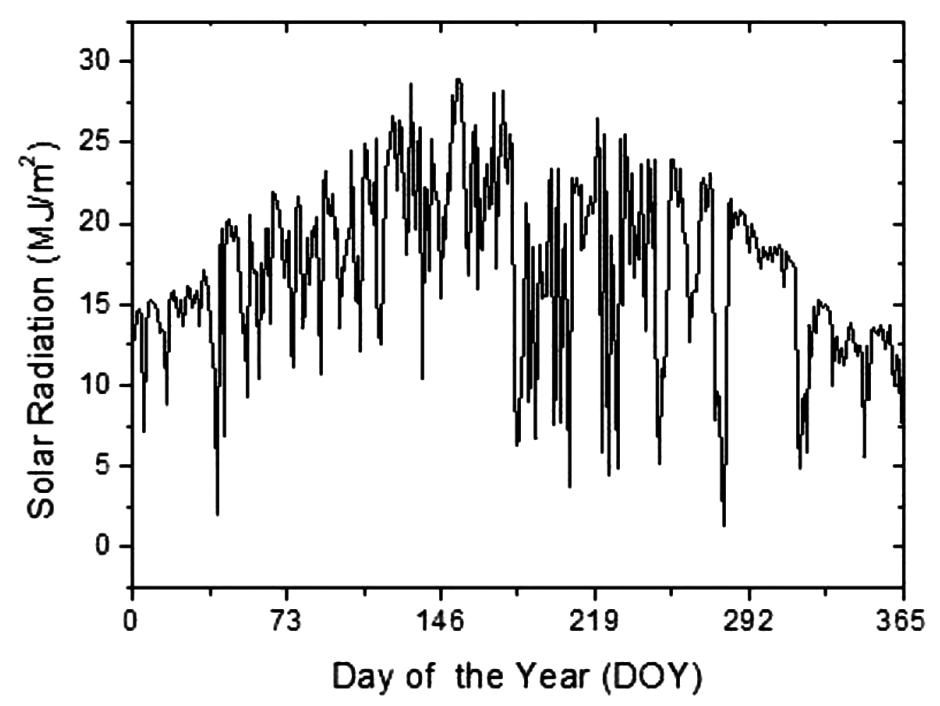

Figure 2 Daily Variation of Global Solar Radiation in 2009-2010

\subsection{Monthly Variation of Global Solar Radiation}

Figure 2 show the trend of measured and extra terrestrial global solar radiation is very much similar. However there was maximum solar radiation $23.21 \mathrm{MJ} / \mathrm{m}^{2} /$ day is found in the month of June. The monthly obtained data indicates that the measured data are relevant as well as sufficient to explore the solar energy even in December when GSR is $12.04 \mathrm{MJ} / \mathrm{m}^{2} /$ day.

Monthly mean measured radiation, global extraterrestrial solar radiation, clearness index are presented in given Table 3.1 
Table 3.1: Meteorological Parameters for Pokhara, 2009-2010

\begin{tabular}{|c|c|c|c|c|c|c|}
\hline Month & $\begin{array}{c}\mathrm{n} \\
\text { (hours) }\end{array}$ & $\begin{array}{c}\mathrm{N} \\
\text { (hours) }\end{array}$ & $\mathrm{n} / \mathrm{N}$ & $\begin{array}{c}\mathrm{H}_{\mathrm{g}} \\
\left.\mathrm{MJ} / \mathrm{m}^{2} / \text { day }\right)\end{array}$ & $\begin{array}{c}\mathrm{H}_{0} \\
\left(\mathrm{MJ} / \mathrm{m}^{2} / \text { day }\right)\end{array}$ & $\begin{array}{c}\text { Clearness Index } \\
\mathrm{K}_{\mathrm{T}}=\mathrm{H}_{\mathrm{g}} / \mathrm{H}_{0}\end{array}$ \\
\hline Jan & 7.7774 & 10.4315 & 0.7453 & 14.2977 & 21.6470 & 0.6613 \\
\hline Feb & 7.3000 & 11.0263 & 0.6622 & 15.6855 & 26.0600 & 0.6023 \\
\hline Mar & 6.9968 & 11.8292 & 0.5917 & 17.8546 & 31.8485 & 0.5632 \\
\hline Apr & 7.3433 & 12.6893 & 0.5802 & 19.4620 & 37.4304 & 0.5216 \\
\hline May & 6.9806 & 13.4076 & 0.5199 & 22.3728 & 40.8376 & 0.5492 \\
\hline Jun & 7.2333 & 13.7666 & 0.5255 & 23.2134 & 42.2038 & 0.5501 \\
\hline Jul & 4.8226 & 13.6034 & 0.3545 & 15.3787 & 41.6992 & 0.3703 \\
\hline Aug & 3.5867 & 12.9994 & 0.2745 & 18.4421 & 38.9382 & 0.4742 \\
\hline Sep & 4.6065 & 12.1714 & 0.3807 & 18.2363 & 34.2082 & 0.5368 \\
\hline Oct & 7.6733 & 11.3119 & 0.6798 & 17.0272 & 28.1934 & 0.6111 \\
\hline Nov & 6.1290 & 10.5969 & 0.5774 & 13.9031 & 22.8391 & 0.6067 \\
\hline Dec & 8.0903 & 10.2442 & 0.7896 & 12.0415 & 20.3490 & 0.5920 \\
\hline
\end{tabular}

\subsection{Estimation of global solar radiation using sunshine duration}

Global solar radiation is backbone for existence of life on the earth. Its measurement is too expensive, time consuming, risk of maintenance and calibration of the instruments. Therefore, it has been great importance to propose an efficient option to be used as a solar estimator based on other more readily available meteorological data. Several empirical models for calculating GSR are recommended in literature. Some of these models use variables like sunshine durations, air temperatures, relative humidity and cloudiness $[8,9,10]$.

The values of sunshine duration including day length, fraction of sunshine hours, GSR, extraterrestrial solar radiation and clearness index are used to estimate regression coefficients "a" and "b". On the basis of the regression coefficients and sunshine duration we could estimate the GSR for the years 2011 and 2012 at the same location.

Among the many empirical equations, the most widely used one is modified Angstrom empirical equation [11,12]. It is selected for the estimation of GSR in, Pokhara. Finally, using the linear regression method we found regression coefficients "a" and "b" which is shown in Table 3.1

Table 3.2: Regression coefficients at Pokhara of Nepal

\begin{tabular}{|c|c|c|}
\hline Location /Coefficients & $\mathrm{a}$ & $\mathrm{b}$ \\
\hline Pokhara & 0.43 & 0.23 \\
\hline
\end{tabular}

Hence the first order polynomial equation for Pokhara as explained by the given equation

$\frac{H g}{H 0}=0.43+0.23\left(\frac{n}{N}\right)$ 
The equation (5) used to estimate the GSR using the regression coefficients obtained in this study and sunshine duration measured at that particular location [13]. Figure 3.3 gives the comparison between measured values of GSR with predicted values of GSR in these three locations. The given Figure 3.3 showed that there is remarkable agreement between the measured and predicted values of GSR in Pokhara..However there is small variation during the time of rainy season.

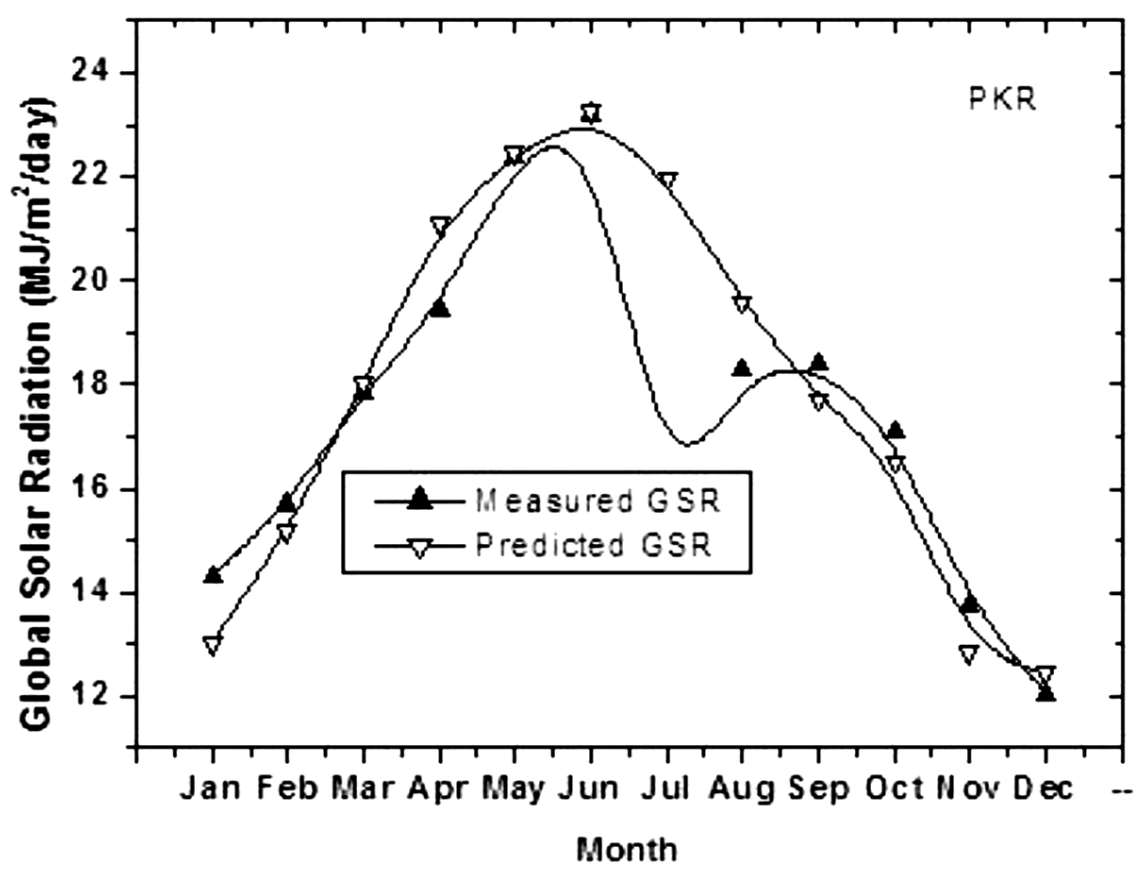

Figure 3: The comparison of measured GSR with predicted GSR At Pokhara (2009-2010)

The regression coefficients "a" and "b" are also called empirical constants and as earlier pointed out their values depend on latitude, relative sunshine hours, altitude, relative humidity, maximum air temperature and so on. The physical significance of the regression constants is that "a" represents the case of overall atmospheric transmission for an overcast sky condition i.e. $n / N=0$, while the coefficient "b" is the rate of increase of $\mathrm{Hg} / \mathrm{H}_{0}$ with $\mathrm{n} / \mathrm{N}$. The sum of two correlation coefficient $\mathrm{a}+\mathrm{b}$ significantly represents the overall transmission under clear sky condition or clear sky index suggested by [14]. The performance of the predicted GSR was statistically compared with measured GSR data. The values of root mean square error (RMSE) mean bias error (MBE) and mean percentage error (MPE) and coefficient of determination $\left(\mathrm{R}^{2}\right)$ are $0.13 \mathrm{MJ} / \mathrm{m}^{2} /$ day, 0.02 $\mathrm{MJ} / \mathrm{m}^{2} /$ day, 6 percent , and 0.70 respectively. All the values are significant range. The values of MBE and MPE are very small and their values are closer to zero and they are highly significant up to the long term performance.

\subsection{Estimation of GSR using regression coefficients and sunshine duration}

The modified Angstrom relation is used to estimate the GSR and regression coefficients. The obtained regression coefficients from the year 2009-2010 are used to estimate the GSR for the years 2011 and 2012. The model estimated values of GSR of Pokhara is comparatively higher than the measured values. So that the estimated value is over estimated. The statistical parameters RMSE, MBE, MPE and $\mathrm{R}^{2}$ are $3.41 \mathrm{MJ} / \mathrm{m}^{2} /$ day, $2.61 \mathrm{MJ} / \mathrm{m}^{2} /$ day, 4 percent, 0.96 , and $-5.48 \mathrm{MJ} / \mathrm{m}^{2} /$ day, $3.84 \mathrm{MJ} / \mathrm{m}^{2} /$ day, 11 percent, 0.83 , in 2011 and 2012 respectively. It concluded that the adopted 
model gives the best estimated values of GSR. The measured value of GSR versus estimated value of graphs is shown in figures 3.3 and 3.4.
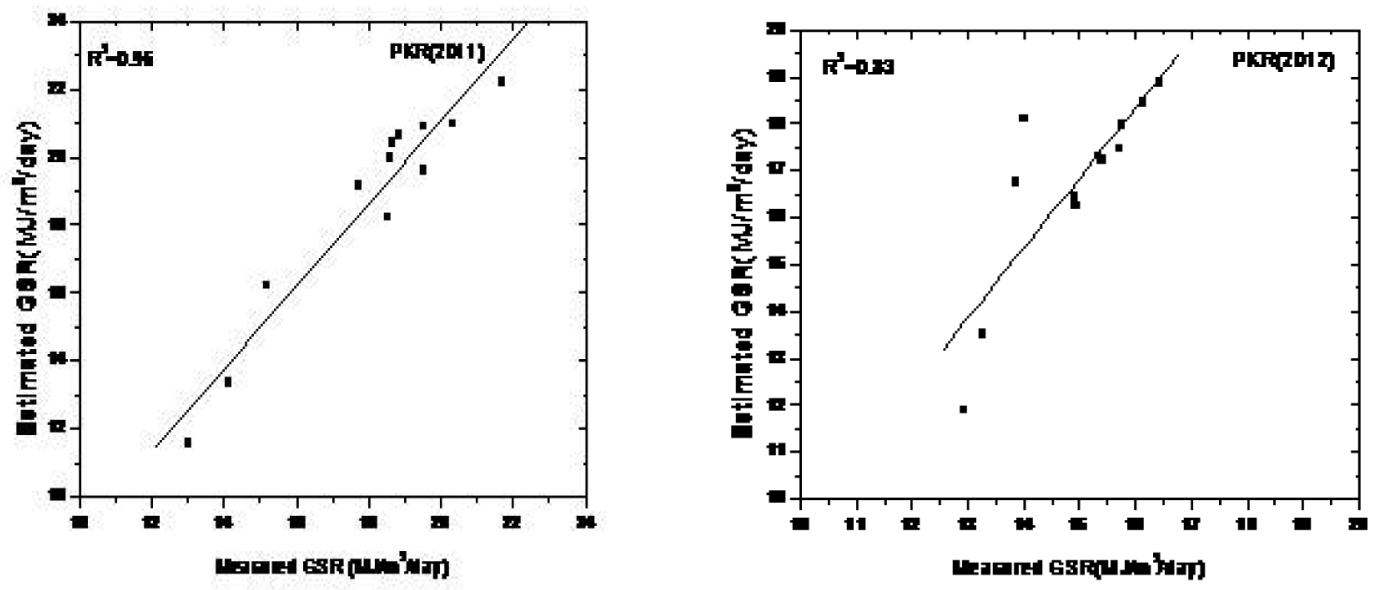

Figure 4 and 5: Comparison between measured and estimated GSR in Pokhara in 2011 and 2012

\section{Conclusion}

The prediction model is developed using monthly average daily values of clearness index, relative sunshine hour, and measured global solar radiation. The maximum and minimum values of monthly average global solar radiation are found $23.21 \mathrm{MJ} / \mathrm{m}^{2} /$ day and $12.04 \mathrm{MJ} / \mathrm{m}^{2} /$ day on June and December respectively. The overall performance of parameters RMSE, MBE, MPE and $\mathrm{R}^{2}$ are found $0.13 \mathrm{MJ} / \mathrm{m}^{2} /$ day, $0.02 \mathrm{MJ} / \mathrm{m}^{2} /$ day, 5 percent, and 0.70 respectively. The above results showed that the estimated values of global solar radiation can be very efficiently used to compensate for the energy deficit. At the end, the obtained regression coefficients from the equation and sunshine duration could be employed for the estimation of global solar radiation in the year to come at the same location.

Acknowledgement: Authors are grateful to express thanks to Solar Radiation and Aerosol in Himalaya Region (SAHR) project of IOE Pulchowk (Nepal) for providing the data of Pyranometer. The support provided by the Prof. Balkrishna Sapkota, Prof. Binod K Bhattarai, Prof. B. P. Pokharel, Prof. R.K. Sharma, Asso. Prof. N.P. Sharma, faculty members and staffs of Department of Engineering Science and Humanities, Pulchowk Campus is highly acknowledged.

\section{References}

[1] WECS,2010, Water and Energy Commission Secretariat, "Energy Synopsis Report", Government of Nepal.

[2] El-Sebaii, AA, Al-Ghamdi, FS, Al-Hazmi, Adel S. Faidah, (2009), Estimation of Global Solar Radiation on horizontal surfaces in Jeddah, Saudi Arabia Energy Policy 37, 3645-3649.

[3] Iqbal M, (1983), An Introduction to Solar Radiation, Academic Press New York.

[4] Sayigh AA (1977), Estimation of Total Radiation Intensity - A Universal Formula. In Mancini, N.A. and Quercia, I.F. (Eds.) 4th Course on Solar Energy Conversion, Vol. II; ICTP, Trieste, Italy, 
164 Estimation of Global Solar Radiation using Modified Angstrom Empirical formula on the basis.......

[5] Klein SA (1977), Calculation of Monthly Average Isolation on Tilted Surfaces Solar Energy, 19, 307-311.

[6] Kipp and Zonen,, (2008). Instruction Manual.

[7] Duffie JA and Beckman WA (1991), Solar Engineering of Thermal Processes, 2nd Edition John Wiley and Sons, New York. NY.

[8] Mengas HO, Ertekin C, and Sonmete MH (2006), "Evaluation of Solar radiation models for Kong a Tur key", Energy Conversion and Management 47, 3146-73.

[9] Poudyal KN, Bhattarai BK, Kjeldstad B and Sapkota BK (2011), Solar Radiation Potential at Four Sites of Nepal, Journal of the Institute of Engineering, NUTA/IOE PCU/SAHR, 8(3),189-197.

[10] Poudyal KN, Bhattarai BK, Sapkota BK and Kjeldstad B (2012), "Estimation of Global Solar Radiation using Sunshine Duration in Himalaya Region", Research Journal of Chemical Sciences, 2(11), 20-25.

[11] Angstrom A (1924), Solar and terrestrial radiation. Quart.J. Roy., Meteo. Soc., 50, 121-125.

[12] Prescott JA (1940), Evaporation from a water surface in relation to solar radiation. Tran. Roy, Soc. So. Aust. 64, $114-118$.

[13] Poudyal KN (2015), "Estimation of Global Solar Radiation Potential in Nepal" Doctoral Thesis at IOE 2015, Institute of Engineering, Pulchowk Campus, Tribhuvan University, Kathamndu

[14] Ogolo EO (2010), "Evaluating the performance of some predictive models for estimating global solar radiation across varying climate condition in Nigeria, Indian Journal of radio and space Physics 39, 121-131. 